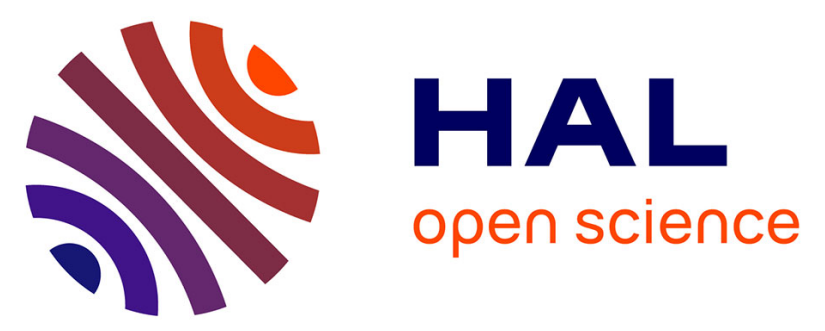

\title{
Multi-class analysis for simultaneous determination of pesticides, mycotoxins, process-induced toxicants and packaging contaminants in tea
}

Mathieu Cladière, Grégoire Delaporte, Even Le Roux, Valérie Camel

\section{To cite this version:}

Mathieu Cladière, Grégoire Delaporte, Even Le Roux, Valérie Camel. Multi-class analysis for simultaneous determination of pesticides, mycotoxins, process-induced toxicants and packaging contaminants in tea. Food Chemistry, 2018, 242, pp.113-121. 10.1016/j.foodchem.2017.08.108 . hal-01637734

\section{HAL Id: hal-01637734 \\ https://hal.science/hal-01637734}

Submitted on 19 Jun 2018

HAL is a multi-disciplinary open access archive for the deposit and dissemination of scientific research documents, whether they are published or not. The documents may come from teaching and research institutions in France or abroad, or from public or private research centers.
L'archive ouverte pluridisciplinaire HAL, est destinée au dépôt et à la diffusion de documents scientifiques de niveau recherche, publiés ou non, émanant des établissements d'enseignement et de recherche français ou étrangers, des laboratoires publics ou privés.

\section{(1) (1) $\$$}

Distributed under a Creative Commons Attribution - NonCommercial - NoDerivatives| 4.0 


\title{
Multi-class analysis for simultaneous determination of pesticides, mycotoxins, process-induced toxicants and packaging contaminants in tea
}

\author{
Mathieu Cladière*, Grégoire Delaporte, Even Le Roux, Valérie Camel.
}

UMR Ingénierie Procédés Aliments, AgroParisTech, Inra, Université Paris-Saclay, 91300 Massy, France Corresponding author*: mathieu.cladiere@agroparistech.fr

\begin{abstract}
This study attempts at uniting the analysis of four different classes of contaminants for both liquid and solid tea samples. A total of 32 compounds, classified as pesticides, mycotoxins, process-induced toxicants or packaging contaminants, were carefully chosen for their diversity of structures and physicochemical properties. The proposed method combines a sample treatment strategy coming from metabolomics with liquid chromatography analysis using a silica bonded C18-pentafluorophenyl column coupled to high resolution mass spectrometry. For tea brew, dilute and shoot method provides good quantification (70-120\% recoveries and $<20 \%$ RSD) for more than $80 \%$ of compounds. For tea leaves, strong matrix effects are observed, thus, matrix-matched calibration is required to reach good performances, i.e. $63 \%$ of compounds quantified and $81 \%$ detected at $10 \mu \mathrm{g} / \mathrm{kg}$. Finally, method performances were evaluated against existing regulations, and it appears that $69 \%$ of contaminants are quantified and $91 \%$ detected at levels lower than their respective European regulation limits.
\end{abstract}

Keyword

Acrylamide; UHPLC-TOF-MS; C18-PFP; food safety; multi-residue analysis 


\section{Introduction}

Food safety remains an everyday challenge toward the globalization of production and sometimes the lack of traceability of products. There are numerous sources of chemical contaminants in food products, ranging from the raw material itself (pesticides, mycotoxins and veterinary drugs in case of food of animal origin), its transportation, its processing (process-induced toxicants), and finally its packaging (migrants). Most analytical strategies, developed by laboratories and food safety authorities around the world, rely on the carrying out of several targeted analyzes in order to cover this broad range of contamination sources and quantify as many contaminants as possible. Such a multi-analysis approach is both very costly and time consuming; on top of that, the environmental footprint of the analysis is increased by the use of larger amounts of solvent and reagent compared with the singleanalysis approach. As a result, recent reviews have underlined the need for multi-class methods capable of analyzing a large number of compounds in a single analysis (Antignac et al., 2011; Castro-Puyana \& Herrero, 2013).

Indeed, the current technology based on liquid chromatography coupled to mass spectrometry (LC-MS) offers the feasibility of developing new approaches thanks to the increasing sensibility and possibility of full scan analysis using high resolution apparatus. As a consequence, few multi-class methods have emerged in recent years (Danezis, Anagnostopoulos, Liapis, \& Koupparis, 2016; Jin et al., 2017; Petrarca, Fernandes, Godoy, \& Cunha, 2016). Yet, although these methods are able to quantify hundreds of contaminants simultaneously, they generally focus on only one or two classes of contaminants with close physicochemical properties. To the best of our knowledge, only one study deals with the analysis of various classes of contaminants including migrants from packaging and process-induced toxicants, but it focuses on LC-MS optimization without assessing efficiency of sample treatment (Pérez-Ortega et al., 2016). The authors pointed out the difficulties of this approach since the structural diversity of targeted compounds leads to heterogeneous behaviors during the LC-MS analysis, both in terms of retention and matrix effects. Consequently, developing a multi-class method capable of analyzing contaminants having a wide-range of chemical structures remains a challenge, particularly in real food matrices due to their complexity.

To reach this objective, tea has been chosen as development matrix for four main reasons. Firstly, this is the most consumed manufactured beverage in the world with 4.8 million tons (of tea leaves) produced in 2013, increasing by $5 \%$ per year since 2008 (Chang, 2015); medium term outlooks suggest a slightly higher increasing of tea consumption (black or green) until 2023. Secondly, tea is produced in remote countries where contamination risks may be difficult to manage; as a consequence, monitoring and regulatory control analyzes regularly show the presence of chemical contaminants (especially pesticide residues) exceeding their European maximum limits (EFSA, 2016). Thirdly, tea can be analyzed in both solid and liquid states, through tea leaves or brew, which is an interesting feature when developing analytical methods for food matrices. Finally, tea is a complex food product regarding its organic composition with a wide variety of phytochemicals (such as antioxidants, aroma compounds, xanthins and alkaloids) which commonly bring strong matrix effects during analysis, therefore making it an interesting real complex food matrix to consider.

This study reports the development and validation of a method for simultaneous extraction and quantification of multi-class contaminants (covering a wide range of chemical structures and properties) for both liquid and solid tea matrices. Until now, this is the first multi-class method covering four classes of food contaminants including pesticides, mycotoxins, process-induced toxicants and migrants from packaging. A total of 32 target compounds were carefully chosen in order to cover the diversity of classes and physicochemical properties encountered. As an illustration, for pesticides, organochlorinated, organophosphates, organosulfites, triazines, auxinic herbicides, neonicotinoids, benzoylureas, pyrazoles, dinitrophenols and carbamates have been considered; as far as we know, all these pesticide families are considered together for the very first time (Eitzer, Hammack, \& Filigenzi, 2014; Hou et al., 2014). In addition, 4 mycotoxins, 2 process-induced toxicants (including acrylamide which has never been considered in any multi-residue method before) and 5 migrants from packaging have been examined. The challenge of our method lies in the different behaviors of these 32 compounds regarding extraction and chromatographic separation, in order to propose the best compromise and provide analytical performances in compliance with the European regulation on food contaminants (European Commission, 2005, 2006). 
Table 1: Targeted compounds along with their instrumental optimized parameters and method performances.

\begin{tabular}{|c|c|c|c|c|c|c|c|c|c|c|c|}
\hline $\mathbf{N}^{\circ}$ & Name & Abbrev. & Class & Chemical family & $\log K_{\text {ow }}$ & \begin{tabular}{|c|} 
RT \\
(min)
\end{tabular} & $\begin{array}{l}\text { ESI } \\
(+/-)\end{array}$ & Ion & $m / \mathbf{z}$ & $\begin{array}{c}\mathbf{L O D} \\
(\mathbf{n g} / \mathbf{m L})\end{array}$ & $\begin{array}{c}\text { LOQ } \\
(\mathrm{ng} / \mathrm{mL})\end{array}$ \\
\hline 1 & Acrylamide & AA & Process-induced & Amide & -0.67 & 1.28 & + & {$[\mathrm{M}+\mathrm{H}]^{+}$} & 72.044 & 5 & 51.5 \\
\hline 2 & Hydroxymethylfurfural & HMF & Process-induced & Furan & -0.09 & 3.11 & + & {$[\mathrm{M}+\mathrm{H}]^{+}$} & 127.039 & 2.5 & 7 \\
\hline 3 & Deoxynivalenol & DON & Mycotoxin & Trichothecene & 0.29 & $\begin{array}{l}3.56 \\
6.24\end{array}$ & $\begin{array}{l}+ \\
-\end{array}$ & $\begin{array}{c}{[\mathrm{M}+\mathrm{H}]^{+}} \\
{[\mathrm{M}-\mathrm{H}]^{-}}\end{array}$ & $\begin{array}{l}297.133 \\
295.119\end{array}$ & 2.5 & 18 \\
\hline 4 & Imidacloprid & IMID & Pesticide (insecticide) & Neonicotinoid & 0.57 & 5.05 & + & {$[\mathrm{M}+\mathrm{H}]^{+}$} & 256.059 & 0.5 & 19.5 \\
\hline 5 & Dimethoate & DIME & Pesticide (acaricide) & Organophosphate & 0.7 & 5.07 & + & {$[\mathrm{M}+\mathrm{H}]^{+}$} & 230.006 & 0.1 & 0.5 \\
\hline 6 & Acetamiprid & ACET & Pesticide (insecticide) & Neonicotinoid & 0.8 & 5.24 & + & {$[\mathrm{M}+\mathrm{H}]^{+}$} & 223.074 & 0.5 & 0.5 \\
\hline 7 & Fumonisin B1 & FB1 & Mycotoxin & Fumonisin & -0.5 & 5.57 & + & {$[\mathrm{M}+\mathrm{H}]^{+}$} & 722.395 & 0.5 & 6.4 \\
\hline 8 & Aldicarb & ALD & Pesticide (acaricide) & Carbamate & 1.15 & 5.63 & + & {$[\mathrm{M}+\mathrm{Na}]^{+}$} & 213.0674 & 0.1 & 0.5 \\
\hline 9 & Ametryn & AME & Pesticide (herbicide) & Triazine & 2.63 & 5.78 & + & {$[\mathrm{M}+\mathrm{H}]^{+}$} & 228.127 & 0.1 & 0.4 \\
\hline 10 & Dichlorvos & DIVO & Pesticide (acaricide) & Organochlorinated & 1.9 & 6.11 & + & {$[\mathrm{M}+\mathrm{H}]^{+}$} & 220.953 & 0.5 & 3.9 \\
\hline 11 & Fumonisin B2 & FB2 & Mycotoxin & Fumonisin & 1.2 & 6.17 & + & {$[\mathrm{M}+\mathrm{H}]^{+}$} & 706.4 & 0.5 & 1.8 \\
\hline 12 & Atrazine & ATZ & Pesticide (herbicide) & Triazine & 2.7 & 6.61 & + & {$[\mathrm{M}+\mathrm{H}]^{+}$} & 216.101 & 0.5 & 1.6 \\
\hline 13 & Diuron & DION & Pesticide (herbicide) & Phenylurea & 2.87 & 7.09 & + & {$[\mathrm{M}+\mathrm{H}]^{+}$} & 233.024 & 0.5 & 9.5 \\
\hline 14 & Ochratoxin A & OTA & Mycotoxin & Ochratoxin & 4.74 & $\begin{array}{c}7.55 \\
10.85 \\
\end{array}$ & $\begin{array}{l}+ \\
-\end{array}$ & $\begin{array}{c}{[\mathrm{M}+\mathrm{H}]^{+}} \\
{[\mathrm{M}-\mathrm{H}]^{-}}\end{array}$ & $\begin{array}{l}404.089 \\
402.075\end{array}$ & $\begin{array}{l}0.5 \\
0.5 \\
\end{array}$ & $\begin{array}{l}19 \\
4.5 \\
\end{array}$ \\
\hline 15 & BFDGE $^{1}$ & BFDGE & Migrant from packaging & Diglycidyl ether & & 8.17 & + & {$[\mathrm{M}+\mathrm{Na}]^{+}$} & 335.125 & 0.5 & 22.8 \\
\hline 16 & Malathion & MLT & Pesticide (insecticide) & Organophosphate & 2.75 & 8.22 & + & {$[\mathrm{M}+\mathrm{H}]^{+}$} & 331.043 & 0.5 & 1.6 \\
\hline 17 & Diflubenzuron & DIFLU & Pesticide (insecticide) & Benzoylurea & 3.89 & 8.46 & + & {$[\mathrm{M}+\mathrm{H}]^{+}$} & 311.039 & 0.5 & 0.8 \\
\hline 18 & BADGE $^{2}$ & BADGE & Migrant from packaging & Diglycidyl ether & & 8.52 & + & {$[\mathrm{M}+\mathrm{Na}]^{+}$} & 363.157 & 4 & 21.2 \\
\hline 19 & Pirimiphos-methyl & PIRI & Pesticide (insecticide) & Organophosphate & 3.9 & 8.72 & + & {$[\mathrm{M}+\mathrm{H}]^{+}$} & 306.103 & 0.1 & 0.6 \\
\hline 20 & 2,4-Dichlorophenoxyacetic acid & $2,4-\mathrm{D}$ & Pesticide (herbicide) & Auxinic herbicide & -0.82 & 9.41 & - & {$[\mathrm{M}-\mathrm{H}]^{-}$} & 218.9621 & 6.9 & 19.4 \\
\hline 21 & Bisphenol S & BPS & Migrant from packaging & Bisphenol & 2.91 & 9.42 & - & {$[\mathrm{M}-\mathrm{H}]^{-}$} & 249.022 & 0.1 & 0.1 \\
\hline 22 & Tolfenpyrad & TOLF & Pesticide (insecticide) & Pyrazole & 5.61 & 9.43 & + & {$[\mathrm{M}+\mathrm{H}]^{+}$} & 384.147 & 0.1 & 0.9 \\
\hline 23 & 2-Methyl-4-chlorophenoxyacetic acid & MCPA & Pesticide (herbicide) & Auxinic herbicide & -0.81 & 9.58 & - & {$[\mathrm{M}-\mathrm{H}]^{-}$} & 199.017 & 1 & 3.6 \\
\hline 24 & Propargite & PROP & Pesticide (acaricide) & Organosulfite & 5.7 & 9.88 & + & Frag $^{3}$ & 231.174 & 0.6 & 3.2 \\
\hline 25 & Dichloprop & DIPRO & Pesticide (herbicide) & Auxinic herbicide & 2.29 & 10.17 & - & {$[\mathrm{M}-\mathrm{H}]^{-}$} & 232.977 & 1.7 & 18.8 \\
\hline 26 & Mecoprop & MCPP & Pesticide (herbicide) & Auxinic herbicide & -0.19 & 10.21 & - & {$[\mathrm{M}-\mathrm{H}]^{-}$} & 213.032 & 0.7 & 1 \\
\hline 27 & 2,4,5-Trichlorophenoxyacetic acid & $2,4,5-\mathrm{T}$ & Pesticide (herbicide) & Auxinic herbicide & 2.88 & 10.61 & - & {$[\mathrm{M}-\mathrm{H}]^{-}$} & 252.9232 & 1 & 4.6 \\
\hline 28 & Bisphenol F & BPF & Migrant from packaging & Bisphenol & 1.65 & 10.73 & - & {$[\mathrm{M}-\mathrm{H}]^{-}$} & 199.076 & 40 & 50 \\
\hline 29 & Fenoprop & $2,4,5 \mathrm{TP}$ & Pesticide (herbicide) & Auxinic herbicide & 2.84 & 11.12 & - & Frag $^{3}$ & 194.917 & 0.8 & 5.3 \\
\hline 30 & Dinoseb & DINO & Pesticide (herbicide) & Dinitrophenol & 2.29 & 11.43 & - & {$[\mathrm{M}-\mathrm{H}]^{-}$} & 239.067 & 0.2 & 0.4 \\
\hline 31 & Bisphenol A & BPA & Migrant from packaging & Bisphenol & 3.3 & 11.51 & - & {$[\mathrm{M}-\mathrm{H}]^{-}$} & 227.107 & 10 & 42 \\
\hline 32 & 4-(2,4-Dichlorophenoxy)butyric acid & 2,4-DB & Pesticide (herbicide) & Auxinic herbicide & 1.35 & 11.62 & - & Frag $^{3}$ & 160.957 & 6.9 & 19.4 \\
\hline
\end{tabular}

BFDGE $^{1}$ : Bisphenol F diclycidyl ether; BADGE²: Bisphenol A diglycidyl ether; Frag ${ }^{3}$ : Fragment 


\section{Materials and methods}

\subsection{Targeted contaminants}

For developing our multi-class method, several target food contaminants were selected from different classes, namely process-induced toxicants $(n=2)$, migrants from packaging $(n=5)$, mycotoxins $(n=4)$, herbicides $(n=11)$, insecticides $(n=6)$ and acaricides $(n=4)$. The selection of these 32 compounds was based on two main criteria; their physicochemical properties to offer a broad range and a large diversity (i.e. hydrophobicity, aromaticity, functional groups) so as to be representative of other contaminants not considered here, and their relevance for tea. As an example, propargite (acaricide) has been quoted 11 times by the European Rapid Alert System for Food and Feed (RASFF) in 2016, leading to border rejections of black and green teas, while acetamiprid and imidacloprid (insecticides) were cited more than 40 times between 2012 and 2015.

The 32 compounds as well as their analytical information are listed in Table 1.

Analytical standards $(100 \mu \mathrm{g} / \mathrm{mL})$ for pesticides, mycotoxins, process-induced toxicants and labelled compounds acrylamide-d3, dimethoate-d6 and malathion-d6 (purity $>99 \%$ ) were supplied by CIL Cluzeau (France). Ochratoxin-d5, bisphenol A, F and S, BADGE, BFDGE and bisphenol A-d14 (purity $>99 \%$ ) were provided by Sigma Aldrich (France).

\subsection{Materials and reagents}

Acetonitrile (ACN) (HPLC plus gradient, LC-MS), water, methanol (MeOH) and formic acid (FA) (all LC-MS grade) were purchased from Carlo Erba. Ultrapure water (Milli-Q ${ }^{\circledR}$ ) was produced by an Integral 3 water purification system from Millipore ${ }^{\circledR}$. The compound used for MS calibration was Leucine Enkephalin (LC-MS grade), purchased from Waters ${ }^{\circledR}$. Magnesium sulphate $\left(\mathrm{MgSO}_{4}\right)$ and sodium citrate $(\mathrm{NaCit})$ salts (analytical grade) were provided by VWR France.

Analyzes of trace contaminants have been performed on a Waters ${ }^{\circledR}$ Acquity H-Class UPLC ${ }^{\circledR}$ system, composed of a quaternary solvent manager pump (QSM), a refrigerated sample manager Flow-Through-Needle (SM-FTN) and a column oven, coupled to a Waters ${ }^{\circledR}$ high resolution mass spectrometer with a Time of Flight analyzer Xevo ${ }^{\circledR}$ G2-S ToF (UHPLC/MS-ToF). An electrospray ionization source was used in both positive (ESI ${ }^{+}$) and negative $\left(\mathrm{ESI}^{-}\right)$modes.

\subsection{Analysis conditions}

\subsubsection{Chromatographic conditions}

Chromatographic separation was done on a column made of silica based particles bonded with C18pentafluorophenyl functions (C18-PFP) (dimensions were $150 \times 2.1 \mathrm{~mm} ; 2 \mu \mathrm{m}$ particles diameter, from ACE, provided by AIT, France). In addition to conventional hydrophobic interactions (provided by $\mathrm{C} 18$ chains), the PFP groups enable hydrogen bonds, $\pi-\pi$ and dipole-dipole interactions, affording a higher capacity for retaining the highly polar compounds (such as acrylamide or acidic herbicides) than a regular C18-silica column.

\subsubsection{MS analysis}

Since different mobile phases were used for positive and negative ionization, analyzes were performed separately for both modes. All analyzes were done using the resolution mode $(30,000 \mathrm{FWHM}$ at $200 \mathrm{~m} / \mathrm{z})$ for a scan time of $0.5 \mathrm{~s}$, with mass range between 60 and $800 \mathrm{~m} / \mathrm{z}$ and data acquired in centroid. Internal calibration of ToF analyzer was performed with a continuous flow at $5 \mu \mathrm{L} / \mathrm{min}$ of Leucine Enkephalin for one scan every $30 \mathrm{~s}$ during $0.1 \mathrm{~s}$.

For $\mathrm{ESI}^{+}$the mobile phase was composed of water (A), ACN (B), both acidified with $0.1 \% \mathrm{FA}$, and $\mathrm{MeOH}(\mathrm{C})$, flowing at $0.4 \mathrm{~mL} / \mathrm{min}$. The gradient started at $100 \% \mathrm{~A}$ and reached $100 \% \mathrm{~B}$ in $10 \mathrm{~min}$, this composition being kept for 6 min before switching to $100 \% \mathrm{C}$ to rinse the system in $1 \mathrm{~min}$, being hold for 5 min, returning back to $100 \% \mathrm{~A}$ in $1 \mathrm{~min}$ and finally equilibrating for $3 \mathrm{~min}$, with a total run duration of $26 \mathrm{~min}$. For ESI-, the mobile phase was composed of water buffered with $10 \mathrm{mM}$ of ammonium formate (A) and $\mathrm{MeOH}$ (B) flowing at $0.3 \mathrm{~mL} / \mathrm{min}$. The gradient started at 100\% A and reached $100 \% \mathrm{~B}$ in $13 \mathrm{~min}$, holding this condition for 7 min before turning back to $100 \% \mathrm{~A}$ in $1 \mathrm{~min}$ and finally equilibrating for $3 \mathrm{~min}$, with a total run duration of $24 \mathrm{~min}$. For both chromatographic methods the column was heated at $30^{\circ} \mathrm{C}$.

The optimized parameters for ESI ${ }^{+}$and ESI ${ }^{-}$are presented in Supplementary data, Table S1.

Based on the instrument factory settings, detection of acrylamide remained unsuccessful. Indeed, the ion path dedicated to discard neutral molecules before analysis (called "StepWave" by Waters ${ }^{\circledR}$, which is the ionic path between the source and the mass analyzer) proved to be the limiting step for small molecules $(\mathrm{m}<90 \mathrm{~m} / \mathrm{z})$. 
Therefore, its settings were set according to Waters ${ }^{\circledR}$ instructions for extending the range of mass detected in a single run $(60-800 \mathrm{~m} / \mathrm{z})$ and ensuring acrylamide detection.

\subsubsection{Quantification and quality controls}

In order to select the best compromise for quantification of targeted contaminants in tea samples, two main quantification methods were considered: solvent calibration and matrix-matched calibration. Each time, classical external calibration was considered and compared with labelled molecules correction.

For external calibration, 11 standard solutions were prepared in a ACN/water mix $(20 / 80 \mathrm{v} / \mathrm{v})$ acidified with $0.1 \%$ FA, with concentrations ranging from 0.1 to $120 \mathrm{ng} / \mathrm{mL}$ for most compounds, except for a few molecules exhibiting lower sensitivity (namely hydroxymethylfurfural (HMF), deoxynivalenol (DON), bisphenol A (BPA) and bisphenol F (BPF)) with concentrations five times higher (from 0.5 to $600 \mathrm{ng} / \mathrm{mL}$ ), as well as acrylamide (AA) with concentrations 10 times higher (1 to $1,200 \mathrm{ng} / \mathrm{mL}$ ).

For labelled molecules correction, deuterated isotopes were used in addition to external calibration, either in positive mode (acrylamide-d3, dimethoate-d6, ochratoxin A-d5 and malathion-d6) and/or in negative mode (ochratoxin A-d5 and bisphenol A-d14). These five molecules were associated to the non-labelled analytes they are supposed to mimic according to their similarities and the closeness of their retention time. All labelled molecules were added before sample treatment in order to reach a concentration in the final extract of $40 \mathrm{ng} / \mathrm{mL}$ for dimethoate-d6, ochratoxin A-d5 and malathion-d6, $200 \mathrm{ng} / \mathrm{mL}$ for bisphenol A-d14 and $400 \mathrm{ng} / \mathrm{mL}$ for acrylamide- $\mathrm{d} 3$.

Last but not least, for matrix-matched calibration, 8 calibration points were prepared directly in sample extract, with concentrations ranging from 2 to $80 \mathrm{ng} / \mathrm{mL}$ (with respectively the same multiplicative factors as for external calibration).

The analytical sequence was randomized and a mobile phase blank as well as a quality standard (standard solution containing all of 32 compounds at $16 \mathrm{ng} / \mathrm{mL}$ ) were analyzed every 10 samples. No cross-contamination was detected during long sequences.

\subsubsection{Data treatment}

The entire data processing was done using open-source, freely available tools. Data files were first converted in mzXML with proteowizard (Chambers et al., 2012), and then processed with MZmine 2 (Pluskal, Castillo, VillarBriones, \& Oresic, 2010), using its "Targeted peak detection" module. When necessary, the instrumental drift along the analytical sequence was addressed by performing "All Loess Pool" correction using the Workflow4Metabolomics Galaxy interface (Giacomoni et al., 2015; van der Kloet, Bobeldijk, Verheij, \& Jellema, 2009). Briefly, analytical drift was modelled based on the quality standard samples, and then the signal was corrected for all samples according to their injection order. Corrected data were then processed with Microsoft Excel.

\subsection{Tea samples and brew preparation}

Tea leaves used for optimization of extraction procedures came from a bulk green tea bought in a tea shop in Paris (France). Tea brew was prepared in accordance with the ISO 3103:1980 norm ensuring a reproducibility of infusion (International Organization for Standardization, 1980). Briefly, $200 \mathrm{~mL}$ tap water were heated at $100^{\circ} \mathrm{C}$ and infusion was prepared using $2 \mathrm{~g}$ of tea leaves weighted in a tea filter and then put in contact with hot tap water for 6 min. Blank sample was performed under the same procedure but without tea leaves, in order to investigate possible contamination from tap water, tea filter, preparation or extraction protocols; no contamination was detected along the analytical process. Non-spiked tea samples were also systematically considered in order to check the absence of native target contaminants (only native HMF could be found in our tea samples), to avoid overestimation of recoveries for the spiking.

\subsection{Sample treatment protocols}

\subsubsection{Tea brew}

Two different sample preparation methods were evaluated for tea brew. These two methods were already developed by other authors as mentioned below, but they needed to be adapted here to match our initial chromatographic conditions (i.e. mobile phase: $100 \%$ water) and our tea matrix.

The first method is based on liquid-liquid extraction (LLE) commonly used for multi-residue analyzes in food products, and adapted from Mol et al. (Hans G. J. Mol et al., 2008). Briefly, $2 \mathrm{~mL}$ of tea brew were mixed with

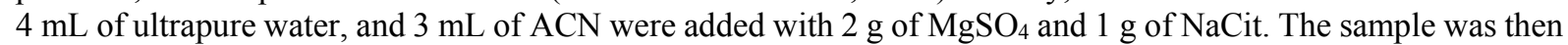
agitated during $1 \mathrm{~h}$ before centrifugation at 3,000 g for $5 \mathrm{~min}$. Aliquot $(1 \mathrm{~mL})$ of supernatant was sampled and diluted with $4 \mathrm{~mL}$ of water. Finally, $0.5 \mathrm{~mL}$ was sampled and filtered at $0.2 \mu \mathrm{m}$ with a syringeless filter (miniuniprep G2, Whatmann) before analysis. 
The second sample treatment tested, named dilute and shoot (D\&S), comes from metabolomic approaches (Tengstrand, Rosen, Hellenas, \& Aberg, 2013). It is intended to favor the analysis of numerous targeted organic compounds in complex matrices. In our case, $2 \mathrm{~mL}$ of tea brew were diluted with $6 \mathrm{~mL}$ of pure water plus $2 \mathrm{~mL}$ of ACN, both acidified with $0.1 \%$ FA, and agitated during $5 \mathrm{~min}$. Then $0.5 \mathrm{~mL}$ of the mixture was sampled and filtered at $0.2 \mu \mathrm{m}$ with a syringeless filter (mini-uniprep G2) before analysis.

\subsubsection{Tea leaves}

Tea leaves were crushed with a pestle and a mortar in order to obtain a homogenous powder. Firstly the extraction protocol described by Mol et al. (2008) (using water and acetonitrile containing formic acid - "proposed method A") was chosen. This method derives from QuEChERS extraction protocols that proved their efficiency for multiresidue analyses in food samples (recoveries between 80 and 110\%) (Dong \& Xiao, 2017; Dzuman, Zachariasova, Veprikova, Godula, \& Hajslova, 2015), except that the dispersive solid-phase clean-up step has been removed to avoid losses of targeted compounds. In addition, considering the low sensitivity and high matrix effects for some compounds, changes were required. In particular, an evaporation step was needed and acidified ACN was selected to recover the dry residue as inspired by Cotton et al. (2014). Since this solvent was unable to recover fumonisins B1 and B2, two more options were further investigated to improve the efficiency of the extraction: 1) increasing the percentage of FA or 2) adding MeOH to the mixture (Hans G. J. Mol et al., 2008). The first option led to strong matrix effects for acrylamide without improving fumonisins recovery. Therefore a mixture of ACN/MeOH $(90 / 10$ $\mathrm{v} / \mathrm{v}$ ) acidified with $0.1 \%$ FA was finally chosen as extracting solvent.

Finally, $5 \mathrm{~mL}$ of $\mathrm{ACN} / \mathrm{MeOH}(90 / 10 \mathrm{v} / \mathrm{v})$ mixture acidified with $0.1 \%$ FA were added to $1 \mathrm{~g}$ and agitated during $1 \mathrm{~h}$ before centrifugation at 3,000 $\mathrm{g}$ for $5 \mathrm{~min}$. Then, the supernatant was collected and an aliquot (1 mL) was evaporated to dryness under a gentle stream of nitrogen. The extract was further reconstituted in $0.2 \mathrm{~mL}$ of ACN $+0.1 \%$ FA. Then $0.8 \mathrm{~mL}$ of ultrapure water with $0.1 \%$ FA was added in order to reconstitute $1 \mathrm{~mL}$ of final volume. Finally, $0.5 \mathrm{~mL}$ were sampled and filtered at $0.2 \mu \mathrm{m}$ using syringeless filters (mini-uniprep G2) before analysis.

\subsection{Method validation}

Instrumental limits of detection and quantification (LOD, LOQ) were evaluated based on repeatability and reproducibility of analyzes of standard solutions at different low levels (from 0.1 to $100 \mathrm{ng} / \mathrm{mL}$ ). For each level, 3 replicates were analyzed 5 times. Relative standard deviation (RSD) was plotted against concentration for each compound, and LODs or LOQs were then graphically assessed when RSDs reached 30\% or 10\% respectively according to IUPAC recommendation (Currie, 1995; Thompson, Ellison, \& Wood, 2002). The overall method limits of quantification (MLOQs) were determined according to the guideline from the SANTE document of the European Commission - Directorate General for Health and Food Safety (2015) by the lowest spiked level reaching the following criteria: recovery $70-120 \%$ and RSD $<20 \%$.

Trueness and precision were evaluated based on triplicates spiked with a mixture solution of all investigated contaminants. Spiking levels were established in accordance with the European regulation for some contaminants (such as maximum residue limits for pesticides) or the lowest concentration expected for other contaminants. Thus, for tea brew, spiking levels were $10 \mathrm{ng} / \mathrm{mL}$ for level 1 and $100 \mathrm{ng} / \mathrm{mL}$ for level 2 for most of compounds, and 50 $\mathrm{ng} / \mathrm{mL}$ (level 1) and $500 \mathrm{ng} / \mathrm{mL}$ (level 2) for the less sensitive compounds (AA, HMF, DON, BPA, BPF). For tea leaves, three levels were set: 10,50 and $100 \mu \mathrm{g} / \mathrm{kg}$ for most of compounds; 50,250 and $500 \mu \mathrm{g} / \mathrm{kg}$ for HMF, DON, BPA and BPF; 100, 500 and 1,000 $\mu \mathrm{g} / \mathrm{kg}$ for AA. Spiking was performed with $100 \mu \mathrm{L}$ of standard solution in ACN followed by equilibrium overnight. For non-spiked samples, $100 \mu \mathrm{L}$ of ACN was added. The trueness was considered acceptable for recoveries between 70 and 120\%, and precision (assessed by RSD) lower than 20\% was required (European Commission - Directorate General for Health and Food Safety, 2015; H. G. J. Mol, Reynolds, Fussell, \& Štajnbaher, 2012).

\section{Results and discussion}

\subsection{Choice of analytical conditions and validation}

\subsubsection{Chromatographic separation}

The first challenge for the chromatographic separation was the retention of acrylamide, since it is a very small and highly polar molecule $(\log \mathrm{Kow}=-0.67)$. This probably explains why acrylamide has never been considered in a multi-residue approach, as its physicochemical properties are too far from those of the other contaminants.

A preliminary test performed on a Hypersil C18 Gold column $(150 \times 2.1 \mathrm{~mm}$ and $2 \mu \mathrm{m}$ particles, Thermo Fisher Scientific) gave a retention factor $(\mathrm{k})$ value of 0.33 , showing insufficient acrylamide retention, probably due to the fraction of ACN in the extract (20\%) that was needed to avoid severe losses of hydrophobic compounds upon extract filtration (PTFE filter). Facing the impossibility to change the fraction of ACN, the only choice was to change the stationary phase of the column. Therefore the C18-PFP phase, combining the strength of C18-chains 
(hydrophobicity) and PFP-groups (hydrogen bonds, dipole-dipole and $\pi-\pi$ interactions) and affording possible enhanced retention of polar compounds, has been chosen. To date, while some studies combined C18 and PFP phases using two successive columns in LCxLC applications (Mena-Bravo, Priego-Capote, \& Luque de Castro, 2016), only two applications dealing with a C18-PFP column have been published yet, for analyzes in rat plasma (Zgair et al., 2015) and markers of lung cancer in human serum (Klupczynska et al., 2017). Thus, the potential of this new stationary phase for the separation of multi-class contaminants in food samples is described here for the first time. Retention tests for acrylamide on C18-PFP with the previously mentioned conditions revealed a $\mathrm{k}$ value about 1.16, showing a significant enhancement of acrylamide retention on this stationary phase, still operating in a reversed phase mode. Such a retention factor above 1 opens new perspectives for the separation of acrylamide from the very first matrix compounds eluting with the dead volume (dead time near 0.6 min here - see Figure 1). Dealing with highly polar compounds is an important challenge for multi-class analysis as pointed out by PérezOrtega et al., who faced the co-elution of most polar compounds (among hundreds of targeted contaminants) with the dead volume upon analysis using a conventional C18-silica stationary phase, resulting in poor analytical performances (Pérez-Ortega et al., 2016). New combined phases such as C18-PFP may represent key tools to solve retention problems of very polar compounds in multi-class contaminants analysis on reversed phase columns.
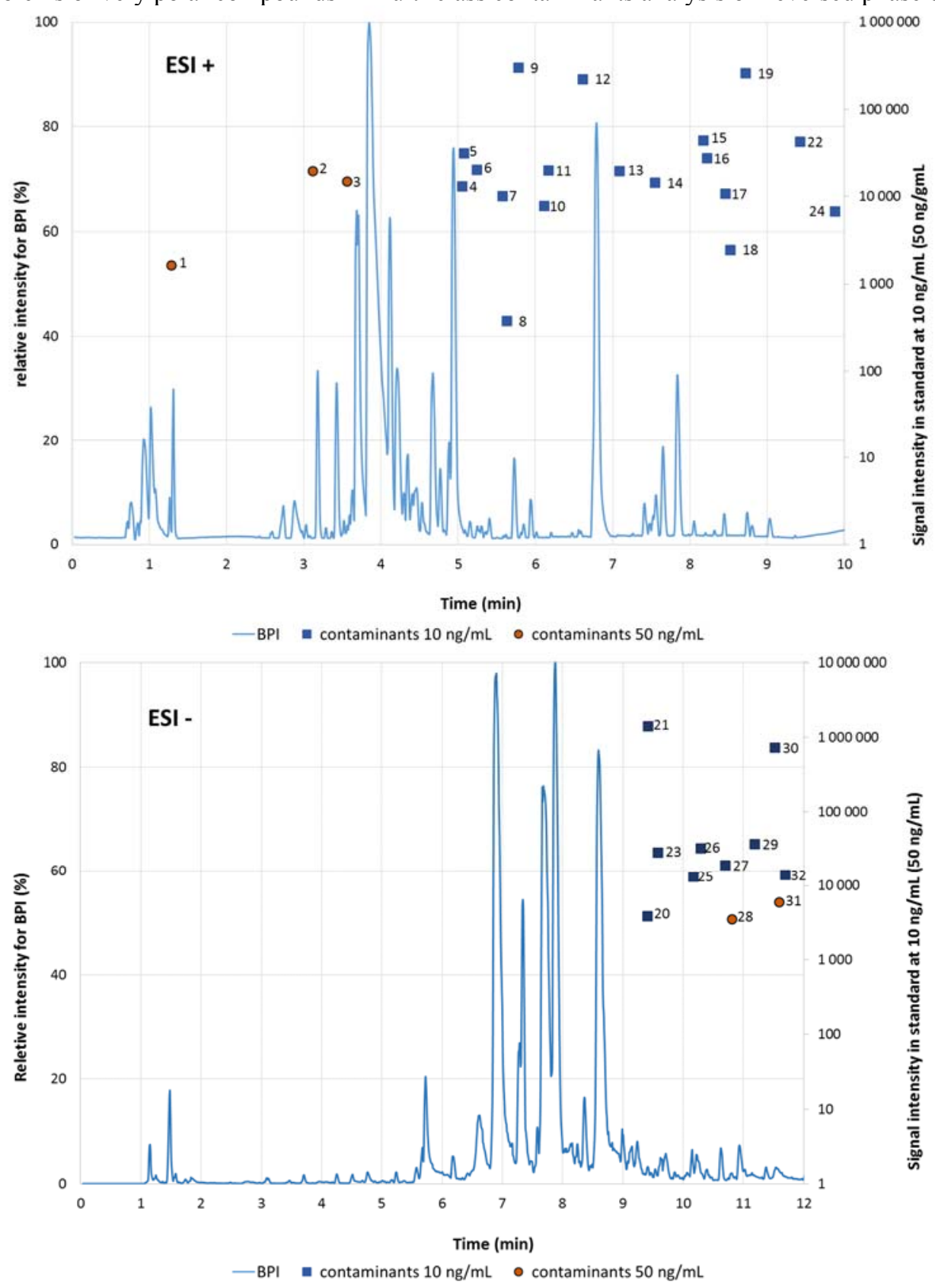

Figure 1 : Base Peak Ion chromatogram (BPI) of tea leave extracts along with signal intensity and retention of targeted contaminants in ESI + and ESI- 
The second challenge for the chromatographic separation is to ensure a good distribution of compounds along the analysis to reduce the probability of co-elution of compounds (with associated potential interferences) as highlighted by Pérez-Ortega et al. (Pérez-Ortega et al., 2016). Such a good separation of compounds is particularly crucial for very complex matrices like food products since they contain several thousands of molecules. Figure 1 displays the distribution of compounds all along the chromatographic run, and the effective separation of targeted contaminants from the major ions of the BPI of tea extracts. Limiting co-elution of targeted contaminants and major compounds (such as polyphenols, caffeine, amino acids) of tea may play a key role in reducing matrix effects as discussed below.

\subsubsection{MS analysis}

Table 1 displays some information about the 32 targeted compounds such as their class, log Kow, retention time and quantification ion selected. In $\mathrm{ESI}^{+}$, most of compounds where analyzed using $[\mathrm{M}+\mathrm{H}]^{+}$ion; in the case of aldicarb, BADGE and BFDGE, the most abundant ion was $[\mathrm{M}+\mathrm{Na}]^{+}$adduct. For propargite, although $[\mathrm{M}+\mathrm{Na}]^{+}$ adduct was still the most abundant, a fragment was used instead for quantification since the $[\mathrm{M}+\mathrm{Na}]^{+}$adduct signal showed interfering ions. In ESI-, most of compounds were analyzed using $[\mathrm{M}-\mathrm{H}]^{-}$ion, except some acidic herbicides for which fragmentation occurred (in that case, the most abundant and specific fragment was selected for quantification). This fragmentation was suspected to occur in the StepWave which is a specificity of some Water ${ }^{\circledR}$ mass spectrometers, as the energy involved to curve the trajectory of ions is higher than the energy needed to fragment some molecules $(3 \mathrm{eV})$ leading to in-instrument fragmentation. Therefore, the intensities of these fragments are specific of the instrument we used and may not be as intense on other HRMS analyzers set in full scan mode.

\subsubsection{Instrumental performances}

Table 1 shows instrumental LODs and LOQs for our targeted contaminants using our LC-HRMS system. LOQs range from $0.1 \mathrm{ng} / \mathrm{mL}$ for BPS to $50 \mathrm{ng} / \mathrm{mL}$ for BPF. Generally speaking, for most investigated contaminants, our estimated LOQs are higher than LOQs mentioned in the literature for targeted analytical methods. For example a recent study reported LOQ as low as $5 \mathrm{ng} / \mathrm{mL}$ for acrylamide in standard solution while the current method only reaches $51.5 \mathrm{ng} / \mathrm{mL}$ (Troise, Fiore, \& Fogliano, 2014). For pesticide compounds the gap is tighter since most of recent studies deal with multi-residue analysis, except for acidic herbicides because of the fragmentation of those compounds in our instrument (LOQ ranging from 4.6 to $19.4 \mathrm{ng} / \mathrm{mL}$ ) (Hou et al., 2014). The slightly higher LOD and LOQ values for our method were expected since they are linked to the compromise required for multi-class analysis of contaminants exhibiting wide differences in their physicochemical properties, meaning that individual optimization of instrumental conditions (LC and MS) is impossible.

\subsection{Sample treatment recoveries}

\subsubsection{Tea brew}

For tea brew, two sample treatments commonly used for multi-residues analyzes were compared, namely LLE and D\&S. Considering the moderate matrix effects observed, quantification was performed using labelled molecules correction here (matrix-matched calibration was not needed).

The percent of the 32 compounds in the different recovery ranges for LLE and D\&S at two spiking levels (10 and $50 \mathrm{ng} / \mathrm{mL}$ for most compounds) are displayed in Figure 2, while the complete results for recoveries and RSDs are gathered in supplementary Data Table S2. 


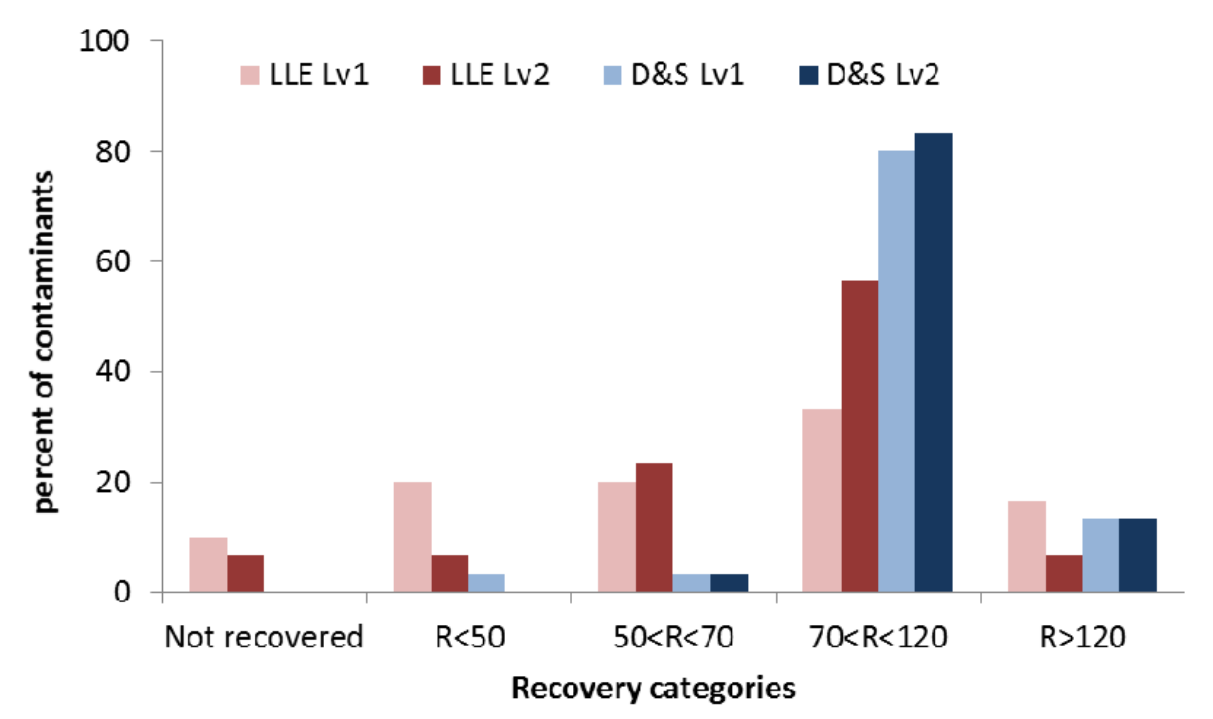

Figure 2: Percentage of 32 target contaminants in recovery range for spiked tea brew. (Lv1: $10 \mathrm{ng} / \mathrm{mL}$ for most compounds except $50 \mathrm{ng} / \mathrm{mL}$ for AA, HMF, BPA, BPF, DON; Lv2: $100 \mathrm{ng} / \mathrm{ml}$ for most compounds except $500 \mathrm{ng} / \mathrm{mL}$ AA, HMF, BPA, BPF, DON)

Based on guidelines for multi-residue analysis proposed by Mol et al. (2012) and the European Commission (European Commission - Directorate General for Health and Food Safety, 2015), the recovery range should be 70 $-120 \%$ and the precision (RSD) lower than $20 \%$ in order to validate quantification of compounds. In the case of multi-residue analysis, recoveries lower than $70 \%$ are acceptable for some compounds provided that RSDs are low (European Commission - Directorate General for Health and Food Safety, 2015). With the D\&S method, all compounds were detected at the lowest level, while 80 and $83 \%$ of target compounds for levels 1 and 2 respectively met the quantification criteria. The percentages were much lower for LLE method with 33\% for level 1 and $60 \%$ for level 2. Surprisingly, whatever the level considered, tolfenpyrad and propargite were not recovered by LLE despite their hydrophobicity $\left(\log \mathrm{K}_{\mathrm{ow}}>5\right)$; on the opposite, both compounds reached 86 and $92 \%$ recoveries at 10 $\mathrm{ng} / \mathrm{mL}$ using the D\&S method. No similar results or explanation was found in the literature. Nonetheless, considering the European RASFF alerts for tea, these two pesticides are commonly cited so that their quantification at low concentrations is crucial. D\&S method led to some overestimations ( $\mathrm{R}>120 \%$ ) especially for fumonisins B1 and B2 with respectively 178 and $161 \%$, possibly due to matrix effects since similar signal enhancement was found in tea leaves (Figure 3) and reported in the literature (Zhang et al., 2016).

The repeatability of extraction, based on triplicates per level, revealed that for level 1 using D\&S preparation, $90 \%$ of compounds have an acceptable RSD $(<20 \%)$, when this value dropped to $60 \%$ for LLE. For D\&S, only HMF, acrylamide and 2,4-D showed RSDs higher than 20\% owing to native contamination for the former and a signal close to the quantification limits of overall method for the latter. For level 2, 96\% of compounds met the requirement of repeatability for D\&S, but only $79 \%$ in the case of LLE.

At last, considering the overall results, the D\&S method seems more appropriate for contaminants quantification in tea brew.

\subsubsection{Tea leaves}

\section{- Matrix effects}

Matrix effects were determined based on comparison between external calibration and matrix-matched calibration. The ratio of slopes from both calibration curves (external / matrix-matched), shown in Figure 3, is informative on the presence of matrix effects for $\mathrm{ESI}^{+}$and $\mathrm{ESI}^{-}$. 


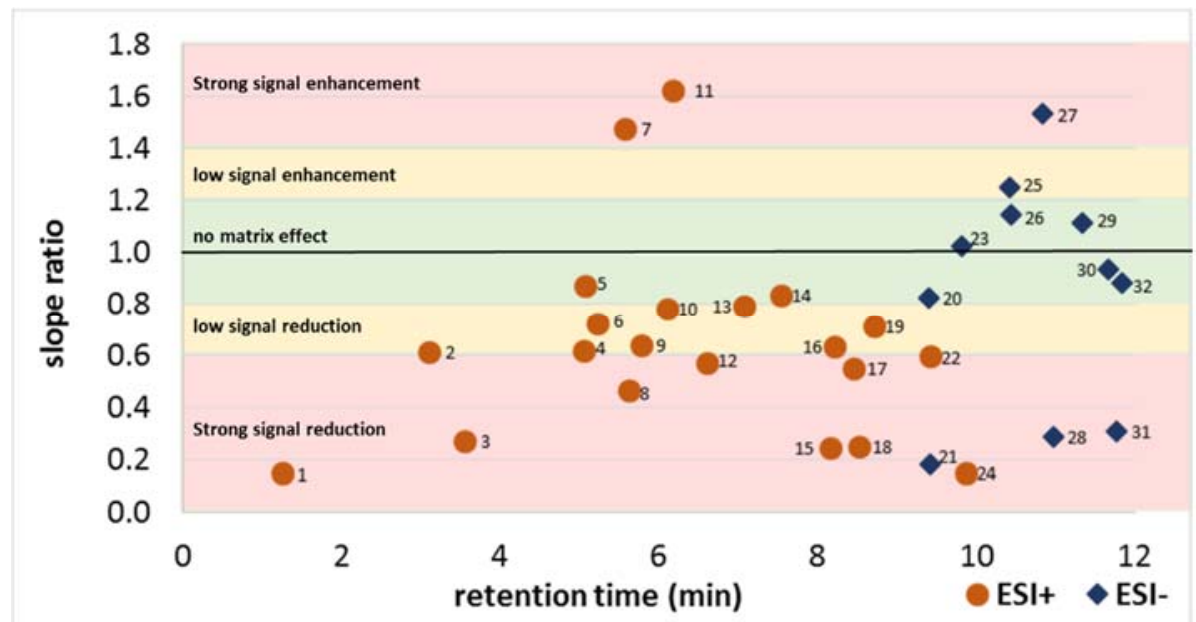

Figure 3 : Matrix effects observed upon analysis of tea leave extracts.

Based on these results, 8 compounds (25\% of target contaminants) do not undergo significant matrix effects (essentially in $\mathrm{ESI}^{-}$), 17 compounds (around 50\%) present low matrix effects (ratios between 0.6 and 1.4), while for the remaining compounds strong matrix effects were observed, mainly with signal suppression. Only fumonisins $\mathrm{B} 1$ and $\mathrm{B} 2\left(\mathrm{ESI}^{+}\right)$and 2,4,5-T $\left(\mathrm{ESI}^{-}\right)$revealed strong signal enhancement. According to our results no correlation between matrix effects and retention time was observed. These results are close to those reported by Mol et al. (Hans G. J. Mol et al., 2008) for other types of food (feed, maize, milk) on 172 analytes showing more intense signal reductions for methanol extraction than for acetonitrile. Signal enhancement for fumonisin B1 was also reported by Danezis et al.(Danezis et al., 2016) for most of foods studied (between 163 and 175\% of standard signals). Our results are in agreement with Dzuman, Zachariasova, Veprikova, Godula, \& Hajslova (2015) who reported 65\% overall signal suppression for hundreds of contaminants in tea using a QuEChERS approach.

\section{- Recoveries}

The recoveries were determined based on three different calibration methods: external standard, labelled molecules correction and matrix-matched calibration.

With the use of labelled molecules, in order to correct the extraction losses and matrix effects, the 32 molecules were corrected by the most relevant labelled molecules of our mix (close retention time and related physicochemical properties). In that case, our results underline decreases of overall recoveries as compared to the use of external calibration. Hence, at 10 and $50 \mu \mathrm{g} / \mathrm{kg}$ only $38 \%$ of molecules meet the requirement for recovery (70-120\%) for external calibration, and this percentage drops respectively to 28 and $31 \%$ at 10 and $50 \mu \mathrm{g} / \mathrm{kg}$ using labelled molecules correction. This drop is surprising since labelled correction (also called isotope dilution) is often used for quantification of contaminants in various food matrices (European Commission - Directorate General for Health and Food Safety, 2015). It has been attributed to strong matrix effects in ESI- analyzes due to the absence of clean-up. Indeed, ochratoxin A-d5 undergoes a strong signal enhancement in negative mode (value ratio: 2.2) which affects quantification of compounds after labelled correction. Unsurprisingly, the correction of labelled molecules was only efficient for the corresponding non-labelled molecules and, therefore, for matrixmatched calibration we decided to avoid labelled correction for other molecules.

In the case of matrix-matched calibration, recoveries were in accordance with results reported by Kaczyński et al. for 300 pesticides in fish tissues (Kaczyński, Łozowicka, Perkowski, \& Szabuńko, 2017) or by Mol et al. for 258 molecules in different types of food (Hans G. J. Mol et al., 2008), with around 63-78\% of molecules within the recovery range $70-120 \%$ (see detailed results in Table 2). Only six molecules (19\%) were not detected at the first spiking level: fumonisins B1 and B2 and propargite $(10 \mu \mathrm{g} / \mathrm{kg})$, BPA and BPF $(50 \mu \mathrm{g} / \mathrm{kg})$ and acrylamide $(100$ $\mu \mathrm{g} / \mathrm{kg}$ ), owing to a reduced sensitivity of the overall method for these contaminants. Fortunately, BPA, BPF and acrylamide were recovered with satisfying recoveries from spiking level 2 (250 and $500 \mu \mathrm{g} / \mathrm{kg}$ ). On the opposite, fumonisins B1 and B2 as well as propargite exhibited recoveries lower or close to $50 \%$ even at the highest spiking level (Table 2).

At last, the repeatability for the 32 molecules was acceptable since $72 \%$ of compounds have RSD lower than $20 \%$. The high RSD values found for BADGE and BFDGE result from matrix compounds competition for $\mathrm{Na}^{+}$adducts, and in the case of HMF it is attributed to the native presence of this molecule and its isomers at "high" concentration $(\approx 265 \mu \mathrm{g} / \mathrm{kg})$ in tea leaves (Table 2$)$. 
Table 2: Recovery, RSD, method limit of quantification (MLOQ) and maximum residue limit (MRL) for the 32 targeted compounds in tea leaves quantified with matrix-matched calibration.

\begin{tabular}{|c|c|c|c|c|c|c|c|c|c|}
\hline \multirow[t]{2}{*}{$\mathbf{N}^{\circ}$} & \multirow[t]{2}{*}{ Compound } & \multicolumn{2}{|c|}{$\begin{array}{c}\text { Level 1 } \\
(10 \mu \mathrm{g} / \mathrm{kg} \\
\mathrm{a}=50 \mu \mathrm{g} / \mathrm{kg} \\
\mathrm{b}=100 \mu \mathrm{g} / \mathrm{kg})\end{array}$} & \multicolumn{2}{|c|}{$\begin{array}{c}\text { Level } 2 \\
(50 \mu \mathrm{g} / \mathrm{kg} \\
\mathrm{a}=250 \mu \mathrm{gg} / \mathrm{kg} \\
\mathrm{b}=500 \mu \mathrm{g} / \mathrm{kg})\end{array}$} & \multicolumn{2}{|c|}{$\begin{array}{c}\text { Level } 3 \\
(100 \mu \mathrm{g} / \mathrm{kg} \\
\mathrm{a}=500 \mu \mathrm{g} / \mathrm{kg} \\
\mathrm{b}=1000 \mu \mathrm{g} / \mathrm{kg})\end{array}$} & \multirow[t]{2}{*}{$\begin{array}{l}\text { MLOQ } \\
(\mu \mathrm{g} / \mathrm{kg})\end{array}$} & \multirow[t]{2}{*}{$\begin{array}{r}\text { MRL } \\
(\mu \mathrm{g} / \mathrm{kg})\end{array}$} \\
\hline & & $\begin{array}{c}\text { Recovery } \\
\text { (\%) }\end{array}$ & $\begin{array}{l}\text { RSD } \\
(\%)\end{array}$ & $\begin{array}{c}\text { Recovery } \\
\text { (\%) }\end{array}$ & $\begin{array}{c}\text { RSD } \\
(\%)\end{array}$ & $\begin{array}{c}\text { Recovery } \\
(\%)\end{array}$ & $\begin{array}{l}\text { RSD } \\
(\%)\end{array}$ & & \\
\hline \begin{tabular}{|l|}
1 \\
\end{tabular} & Acrylamide $^{\mathrm{b}}$ & ND & - & 86.4 & 19.0 & 110.2 & 21.1 & 500 & - \\
\hline 2 & Hydroxymethylfurfural ${ }^{\mathrm{a}}$ & 89.4 & 77.5 & 51.3 & 41.1 & 51.0 & 23.3 & - & - \\
\hline 3 & Deoxynivalenol $^{\mathrm{a}}$ & 282.4 & 12.1 & 138.6 & 24.1 & 91.7 & 19.8 & 500 & 1,250 \\
\hline 4 & Imidacloprid & 103.8 & 13.0 & 103.8 & 16.1 & 96.5 & 14.9 & 10 & 50 \\
\hline 5 & Dimethoate & 113.8 & 15.8 & 96.6 & 15.8 & 107.0 & 2.4 & 10 & 50 \\
\hline 6 & Acetamiprid & 115.4 & 17.4 & 115.4 & 14.8 & 100.4 & 16.9 & 10 & 50 \\
\hline \begin{tabular}{|l|}
7 \\
\end{tabular} & Fumonisin B1 & ND & - & 13.4 & 58.5 & 22.4 & 5.0 & - & - \\
\hline 8 & Aldicarb & 87.7 & 13.4 & 87.7 & 15.7 & 78.9 & 12.0 & 10 & 50 \\
\hline 9 & Ametryn & 106.3 & 15.3 & 106.3 & 13.3 & 96.5 & 12.1 & 10 & 10 \\
\hline 10 & Dichlorvos & 114.7 & 16.1 & 96.2 & 16.1 & 112.3 & 14.9 & 10 & 20 \\
\hline 11 & Fumonisin B2 & ND & - & 24.6 & 36.9 & 28.7 & 6.1 & - & - \\
\hline 12 12 & Atrazine & 147.9 & 16.9 & 103.5 & 19.6 & 105.8 & 16.4 & 50 & 100 \\
\hline 13 & Diuron & 101.8 & 11.6 & 88.0 & 7.1 & 91.0 & 8.3 & 10 & 50 \\
\hline 14 & Ochratoxin A & 95.1 & 6.1 & 106.6 & 4.1 & 108.7 & 3.6 & 10 & 10 \\
\hline 15 & BFDGE $^{1}$ & 77.4 & 26.4 & 73.1 & 12.0 & 78.9 & 17.0 & 50 & - \\
\hline 16 & Malathion & 108.7 & 5.7 & 105.4 & 3.6 & 106.6 & 2.3 & 10 & 500 \\
\hline 17 & Diflubenzuron & 76.3 & 15.9 & 77.0 & 6.8 & 80.0 & 7.3 & 10 & 100 \\
\hline \begin{tabular}{|l|}
18 \\
\end{tabular} & BADGE $^{2}$ & 107.1 & 51.6 & 105.3 & 11.2 & 103.9 & 16.0 & 50 & 60,000 \\
\hline 19 & Pirimiphos-methyl & 84.6 & 12.4 & 80.1 & 11.3 & 86.5 & 6.1 & 10 & 50 \\
\hline 20 & $2,4-\mathrm{D}$ & 66.1 & 17.8 & 68.8 & 11.6 & 71.4 & 10.0 & 50 & 100 \\
\hline 21 & Bisphenol S & 80.3 & 11.4 & 80.1 & 13.1 & 76.8 & 11.2 & 10 & 50 \\
\hline 22 & Tolfenpyrad & 45.2 & 11.4 & 56.4 & 8.6 & 62.1 & 8.0 & $(50)$ & 10 \\
\hline 23 & MCPA & 73.6 & 8.1 & 94.8 & 10.2 & 71.1 & 10.3 & 10 & 100 \\
\hline 24 & Propargite & ND & - & 38.5 & 18.5 & 52.6 & 20.3 & $(100)$ & 100 \\
\hline 25 & Dichloprop & 83.9 & 18.1 & 91.6 & 19.8 & 87.6 & 15.2 & 10 & 100 \\
\hline 26 & Mecoprop & 79.9 & 6.0 & 98.1 & 12.3 & 74.1 & 11.5 & 10 & 100 \\
\hline 27 & $2,4,5-\mathrm{T}$ & 82.9 & 8.8 & 91.3 & 8.8 & 88.3 & 18.9 & 10 & 50 \\
\hline 28 & Bisphenol F & ND & - & 75.8 & 25.8 & 72.3 & 21.4 & $(500)$ & - \\
\hline 29 & Fenoprop & 76.4 & 5.5 & 71.5 & 9.5 & 70.9 & 8.5 & 10 & 10 \\
\hline 30 & Dinoseb & 62.1 & 6.1 & 66.3 & 15.9 & 60.5 & 11.6 & (10) & 100 \\
\hline 31 & Bisphenol $\mathrm{A}^{\mathrm{a}}$ & ND & - & 78.2 & 36.7 & 74.7 & 22.5 & $(500)$ & 600 \\
\hline \begin{tabular}{|l|}
32 \\
\end{tabular} & $2,4-\mathrm{DB}$ & 61.8 & 17.6 & 68.8 & 11.6 & 72.3 & 8.9 & 100 & 50 \\
\hline
\end{tabular}

$\mathrm{ND}=$ Not detected. Values under bracket mean that validation criteria were not reached but were still acceptable according to the European commission guideline (European Commission - Directorate General for Health and Food Safety, 2015)

- Analytical performances

The MLOQs determined in accordance with the European guidance document (European Commission Directorate General for Health and Food Safety, 2015) clearly show that our method performances are sufficient to ensure the compliance of a tea sample with the maximum residue limits (MRLs) fixed by the European Commission (European Commission, 2005). These results may open routine analysis field to broad-scale multiclass methods within the next years. Among the lowest MRLs set for ametryn, tolfenpyrad and fenoprop at 10 $\mu \mathrm{g} / \mathrm{kg}$ of tea leaves, only tolfenpyrad do not meet the quantification requirement with a recovery around $45 \%$ and RSD of $11 \%$. However, according to the European guidance document, such performances are still acceptable in the case of multi-residue methods (European Commission - Directorate General for Health and Food Safety, 2015). Finally, $69 \%$ of targeted molecules could be quantified at concentrations equal to or lower than their MRLs or usual levels in tea for non-regulated compounds (European Commission, 2005, 2006), and additional $22 \%$ could be detected but not quantified without labelled correction (recoveries below 70\% or above 120\%). As an example, fenoprop and ametryne were correctly quantified at $10 \mu \mathrm{g} / \mathrm{kg}$ (respective recoveries: 76.4 and $89.7 \%$ and RSD $<20 \%$ ) while recovery for tolfenpyrad (about $45 \%$ ) should require correction before quantification. For molecules with low concentration limits, improvement of our method would be to add their corresponding labelled molecule to ensure a correct quantification at low levels. 
Finally, despite the large diversity of the 32 selected compounds coming from 4 different classes of contaminants, our analytical method displays equivalent performances than recent multi-residue methods dedicated for hundreds of compounds belonging to only 1 or 2 classes.

\section{Conclusion}

For the very first time, we have developed an analytical method dedicated to the simultaneous determination of food contaminants belonging to 4 different classes (pesticides, mycotoxins, process-induced toxicants and migrants from packaging) and exhibiting extremely different physicochemical properties. This method, based on metabolomics sample treatment and a new liquid chromatographic column stationary phase coupled to high resolution mass spectrometry, has been validated on 32 target contaminants, ranging from highly polar acrylamide $\left(\log \mathrm{K}_{\mathrm{ow}}=-0.67\right)$ to less polar tolfenpyrad $\left(\log \mathrm{K}_{\mathrm{ow}}=5.61\right)$, in both tea brew and leaves. All these molecules could be detected and correctly quantified at trace levels (near $\mu \mathrm{g} / \mathrm{kg}$ in tea leaves or $\mu \mathrm{g} / \mathrm{L}$ in tea brew) generally below their respective regulation limits. Only fumonisins B1 and B2 could not be quantified at any concentrations assessed in tea leaves due to low recoveries for these molecules, while quantification was correct at $10 \mu \mathrm{g} / \mathrm{L}$ in tea brew. Matrix-matched calibration was required to hinder strong matrix effects for several molecules for tea leaves while only labelled correction was needed for tea brew (lower matrix effects). Our method can be considered as a new step beyond current multi-residue analyzes, and its applicability to other food matrices would be valuable to be investigated in a near future.

This research did not receive any specific grant from funding agencies in the public, commercial, or non-profit sectors.

\section{References}

Antignac, J.-P., Courant, F., Pinel, G., Bichon, E., Monteau, F., Elliott, C., \& Le Bizec, B. (2011). Mass spectrometry-based metabolomics applied to the chemical safety of food. Trac-Trends in Analytical Chemistry, 30(2), 292-301. https://doi.org/10.1016/j.trac.2010.11.003

Castro-Puyana, M., \& Herrero, M. (2013). Metabolomics approaches based on mass spectrometry for food safety, quality and traceability. TrAC Trends in Analytical Chemistry, 52, 74-87. https://doi.org/10.1016/j.trac.2013.05.016

Chambers, M. C., Maclean, B., Burke, R., Amodei, D., Ruderman, D. L., Neumann, S., ... Mallick, P. (2012). A cross-platform toolkit for mass spectrometry and proteomics. Nature Biotechnology, 30(10), 918-920. https://doi.org/10.1038/nbt.2377

Chang, K. (2015). World tea production and trade. Current and future development (p. 17). Rome: food and agriculture organization of the united nations.

Cotton, J., Leroux, F., Broudin, S., Marie, M., Corman, B., Tabet, J.-C., ... Junot, C. (2014). High-Resolution Mass Spectrometry Associated with Data Mining Tools for the Detection of Pollutants and Chemical Characterization of Honey Samples. Journal of Agricultural and Food Chemistry, 62(46), 11335-11345. https://doi.org/10.1021/jf504400c 
Currie, L. A. (1995). Nomenclature in evaluation of analytical methods including detection and quantification capabilities (IUPAC Recommendations 1995). Pure and Applied Chemistry, 67(10), 1699-1723. https://doi.org/10.1351/pac199567101699

Danezis, G. P., Anagnostopoulos, C. J., Liapis, K., \& Koupparis, M. A. (2016). Multi-residue analysis of pesticides, plant hormones, veterinary drugs and mycotoxins using HILIC chromatography - MS/MS in various food matrices. Analytica Chimica Acta, 942, 121-138. https://doi.org/10.1016/j.aca.2016.09.011

Dong, H., \& Xiao, K. (2017). Modified QuEChERS combined with ultra high performance liquid chromatography tandem mass spectrometry to determine seven biogenic amines in Chinese traditional condiment soy sauce. Food Chemistry, 229, 502-508. https://doi.org/10.1016/j.foodchem.2017.02.120

Dzuman, Z., Zachariasova, M., Veprikova, Z., Godula, M., \& Hajslova, J. (2015). Multi-analyte high performance liquid chromatography coupled to high resolution tandem mass spectrometry method for control of pesticide residues, mycotoxins, and pyrrolizidine alkaloids. Analytica Chimica Acta, 863, 29-40. https://doi.org/10.1016/j.aca.2015.01.021

EFSA. (2016). Chemicals in food 2016: Overview of selected data collection (p. 40).

Eitzer, B. D., Hammack, W., \& Filigenzi, M. (2014). Interlaboratory Comparison of a General Method To Screen Foods for Pesticides Using QuEChERs Extraction with High Performance Liquid Chromatography and High Resolution Mass Spectrometry. Journal of Agricultural and Food Chemistry, 62(1), 80-87. https://doi.org/10.1021/jf405128y

European Commission. Regulation (EC) No. 396/2005 of the European Parliament and of the council of 23 February 2005 on maximum residue levels of pesticides in or on food and feed of plant and animal origin and amending Council Directive 91/414/EC., 70 Official Journal of the European Union $\S(2005)$.

European Commission. Regulation (EC) No 1881/2006 of 19 December 2006 setting maximum levels for certain contaminants in foodstuffs, 364 Official Journal of the European Union § (2006).

European Commission - Directorate General for Health and Food Safety. (2015). Guidance document on analytical quality control and method validation procedures for pesticides residues analysis in food and feed. SANTE/11945/2015.

Giacomoni, F., Le Corguille, G., Monsoor, M., Landi, M., Pericard, P., Petera, M., ... Caron, C. (2015). Workflow4Metabolomics: a collaborative research infrastructure for computational metabolomics. Bioinformatics, 31(9), 1493-1495. https://doi.org/10.1093/bioinformatics/btu813 
Hou, X., Lei, S., Qiu, S., Guo, L., Yi, S., \& Liu, W. (2014). A multi-residue method for the determination of pesticides in tea using multi-walled carbon nanotubes as a dispersive solid phase extraction absorbent. Food Chemistry, 153, 121-129. https://doi.org/10.1016/j.foodchem.2013.12.031

International Organization for Standardization. (1980). ISO 3103:1980 - Tea -- Preparation of liquor for use in sensory tests (p. 4).

Jin, Y., Zhang, J., Zhao, W., Zhang, W., Wang, L., Zhou, J., \& Li, Y. (2017). Development and validation of a multiclass method for the quantification of veterinary drug residues in honey and royal jelly by liquid chromatography-tandem mass spectrometry. Food Chemistry, 221, 1298-1307. https://doi.org/10.1016/j.foodchem.2016.11.026

Kaczyński, P., Łozowicka, B., Perkowski, M., \& Szabuńko, J. (2017). Multiclass pesticide residue analysis in fish muscle and liver on one-step extraction-cleanup strategy coupled with liquid chromatography tandem mass spectrometry. Ecotoxicology and Environmental Safety, 138, 179-189. https://doi.org/10.1016/j.ecoenv.2016.12.040

Klupczynska, A., Dereziński, P., Garrett, T. J., Rubio, V. Y., Dyszkiewicz, W., Kasprzyk, M., \& Kokot, Z. J. (2017). Study of early stage non-small-cell lung cancer using Orbitrap-based global serum metabolomics. Journal of Cancer Research and Clinical Oncology, 143(4), 649-659. https://doi.org/10.1007/s00432017-2347-0

Mena-Bravo, A., Priego-Capote, F., \& Luque de Castro, M. D. (2016). Two-dimensional liquid chromatography coupled to tandem mass spectrometry for vitamin D metabolite profiling including the C3-epimer-25monohydroxyvitamin D3. Journal of Chromatography A, 1451, 50-57. https://doi.org/10.1016/j.chroma.2016.05.006

Mol, H. G. J., Reynolds, S. L., Fussell, R. J., \& Štajnbaher, D. (2012). Guidelines for the validation of qualitative multi-residue methods used to detect pesticides in food. Drug Testing and Analysis, 4(S1), 10-16. https://doi.org/10.1002/dta.1364

Mol, Hans G. J., Plaza-Bolaños, P., Zomer, P., de Rijk, T. C., Stolker, A. A. M., \& Mulder, P. P. J. (2008). Toward a Generic Extraction Method for Simultaneous Determination of Pesticides, Mycotoxins, Plant Toxins, and Veterinary Drugs in Feed and Food Matrixes. Analytical Chemistry, 80(24), 9450-9459. https://doi.org/10.1021/ac801557f 
Pérez-Ortega, P., Lara-Ortega, F. J., García-Reyes, J. F., Gilbert-López, B., Trojanowicz, M., \& Molina-Díaz, A. (2016). A feasibility study of UHPLC-HRMS accurate-mass screening methods for multiclass testing of organic contaminants in food. Talanta, 160, 704-712. https://doi.org/10.1016/j.talanta.2016.08.002

Petrarca, M. H., Fernandes, J. O., Godoy, H. T., \& Cunha, S. C. (2016). Multiclass pesticide analysis in fruit-based baby food: A comparative study of sample preparation techniques previous to gas chromatography-mass spectrometry. Food Chemistry, 212, 528-536. https://doi.org/10.1016/j.foodchem.2016.06.010

Pluskal, T., Castillo, S., Villar-Briones, A., \& Oresic, M. (2010). MZmine 2: Modular framework for processing, visualizing, and analyzing mass spectrometry-based molecular profile data. Bmc Bioinformatics, 11, 395. https://doi.org/10.1186/1471-2105-11-395

Tengstrand, E., Rosen, J., Hellenas, K.-E., \& Aberg, K. M. (2013). A concept study on non-targeted screening for chemical contaminants in food using liquid chromatography-mass spectrometry in combination with a metabolomics approach. Analytical and Bioanalytical Chemistry, 405(4), 1237-1243. https://doi.org/10.1007/s00216-012-6506-5

Thompson, M., Ellison, S. L. R., \& Wood, R. (2002). Harmonized guidelines for single-laboratory validation of methods of analysis (IUPAC Technical Report). Pure and Applied Chemistry, 74(5), 835-855. https://doi.org/10.1351/pac200274050835

Troise, A. D., Fiore, A., \& Fogliano, V. (2014). Quantitation of Acrylamide in Foods by High-Resolution Mass Spectrometry. Journal of Agricultural and Food Chemistry, 62(1), 74-79. https://doi.org/10.1021/jf404205b

van der Kloet, F. M., Bobeldijk, I., Verheij, E. R., \& Jellema, R. H. (2009). Analytical Error Reduction Using Single Point Calibration for Accurate and Precise Metabolomic Phenotyping. Journal of Proteome Research, 8(11), 5132-5141. https://doi.org/10.1021/pr900499r

Zgair, A., Wong, J. C. M., Sabri, A., Fischer, P. M., Barrett, D. A., Constantinescu, C. S., \& Gershkovich, P. (2015). Development of a simple and sensitive HPLC-UV method for the simultaneous determination of cannabidiol and $\Delta 9$-tetrahydrocannabinol in rat plasma. Journal of Pharmaceutical and Biomedical Analysis, 114, 145-151. https://doi.org/10.1016/j.jpba.2015.05.019

Zhang, S., Lu, J., Wang, S., Mao, D., Miao, S., \& Ji, S. (2016). Multi-mycotoxins analysis in Pheretima using ultra-high-performance liquid chromatography tandem mass spectrometry based on a modified QuEChERS method. Journal of Chromatography B, 1035, 31-41. https://doi.org/10.1016/j.jchromb.2016.09.022 
